\title{
REVIEW
}

\section{A Delphi Consensus Approach to Challenging Case Scenarios in Moderate-to-Severe Psoriasis: Part 2}

\author{
Bruce E. Strober $\cdot$ Jennifer Clay Cather $\cdot$ David Cohen $\cdot$ Jeffrey J. Crowley $\cdot$ Kenneth B. Gordon $\cdot$ \\ Alice B. Gottlieb • Arthur F. Kavanaugh • Neil J. Korman • Gerald G. Krueger • Craig L. Leonardi • \\ Sergio Schwartzman $\cdot$ Jeffrey M. Sobell $\cdot$ Gary E. Solomon $\cdot$ Melodie Young
}

To view enhanced content go to www.dermtherapy-open.com

Received: September 24, 2011 / Published online: March 30, 2012

(c) The Author(s) 2012. This article is published with open access at Springerlink.com

\section{ABSTRACT}

Introduction: Clinicians may be confronted with difficult-to-treat psoriasis cases for which there are scant data to rely upon for guidance. To assist in managing such patients, who are

B. E. Strober $(\square)$

Department of Dermatology, University of Connecticut School of Medicine, Farmington, CT 06032, USA

e-mail: brucestrober30@me.com

\section{J. Clay Cather}

Division of Dermatology, Department of Internal Medicine, Baylor University Medical Center,

Modern Dermatology, Dallas, TX, USA

\section{Cohen}

Department of Dermatology, NYU Langone Medical Center, New York, USA

\section{J. J. Crowley}

Bakersfield Dermatology and Skin Cancer Medical Group, Bakersfield, CA, USA

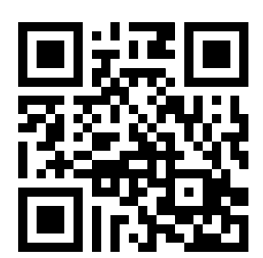

Enhanced content for this article is available on the journal web site: www.dermtherapy-open.com typically excluded from clinical trials, a consensus panel of 14 experts in the field of psoriasis was formed to conduct a Delphi method exercise.

Methods: The exercise consisted of both survey questionnaires and a live meeting to review and

\author{
K. B. Gordon \\ Department of Dermatology, Northwestern \\ University Feinberg School of Medicine, \\ Chicago, IL, USA
}

\section{A. B. Gottlieb · J. M. Sobell}

Department of Dermatology, Tufts Medical Center, Tufts University School of Medicine, Boston, MA, USA

\section{A. F. Kavanaugh}

Division of Rheumatology, Allergy, and

Immunology, Department of Medicine, University of California, San Diego, CA, USA

\section{N. J. Korman}

Department of Dermatology, Case Western Reserve University School of Medicine, Cleveland, $\mathrm{OH}$, USA

\section{G. G. Krueger}

Department of Dermatology, University of Utah, Salt Lake City, UT, USA

\section{L. Leonardi}

Department of Dermatology, St. Louis University

School of Medicine, St. Louis, MO, USA 
discuss current data (as of 2009, when the exercise was conducted) and arrive at a consensus for optimal treatment options. Seventy difficult treatment scenarios were identified, and the top 24 were selected for discussion at the live meeting.

Results: Five of the 24 discussed case scenarios are presented in this article: (1) moderate-to-severe psoriasis that has failed to respond to all currently approved therapies for psoriasis; (2) palmoplantar psoriasis that is unresponsive to topical therapy and phototherapy; (3) erythrodermic psoriasis; (4) pustular psoriasis; and (5) the preferred therapeutic choice to combine with low-dose methotrexate. A previous article (part 1) presented six other scenarios.

Conclusion: The Delphi exercise resulted in guidelines for practicing physicians to utilize when confronted with patients with challenging cases of psoriasis.

Keywords: Acitretin; Biologics; Erythrodermic psoriasis; Palmoplantar psoriasis; Psoriasis; Pustular psoriasis; Methotrexate; TNF- $\alpha$ inhibitor

\section{INTRODUCTION}

Psoriasis is a difficult condition to treat, and it is often accompanied by comorbidities that confound diagnosis and complicate management.

S. Schwartzman

Weill Medical College of Cornell University,

Hospital for Special Surgery, New York Presbyterian

Hospital, New York, NY, USA

G. E. Solomon

Department of Rheumatology, NYU Langone School

of Medicine, New York, NY, USA

M. Young

Graduate School of Nursing, and Modern

Dermatology, University of Texas at Arlington,

Dallas, TX, USA
The literature on such scenarios is sparse, as patients with unusual or complex disease and comorbidities are typically excluded from clinical trials.

A consensus panel of 14 experts in the field of psoriasis was formed to conduct a Delphi method exercise to identify challenging clinical scenarios and to rank treatment approaches, in an effort to provide guidance to the practicing clinician.

Part 1 in this series presented six scenarios from this Delphi exercise: (1) psoriasis and human papilloma virus (HPV)-induced cervical or anogenital dysplasia; (2) concomitant psoriasis and systemic lupus erythematosus; (3) severe psoriatic nail disease causing functional or emotional impairment; (4) psoriasis therapies that potentially reduce cardiovascular morbidity and mortality; (5) older patients ( $\geq 65$ years of age) with psoriasis; and (6) severe scalp psoriasis that is unresponsive to topical therapy [1].

The current paper presents five additional scenarios of interest to the practicing dermatologist: (1) moderate-to-severe psoriasis that has failed to respond to all currently approved therapies for psoriasis; (2) palmoplantar psoriasis (PPP) that is unresponsive to topical therapy and phototherapy; (3) erythrodermic psoriasis; (4) pustular psoriasis; and (5) the preferred therapeutic choice to combine with low-dose methotrexate. These selected scenarios were chosen by the first author (B.E.S.).

\section{THE DELPHI METHOD}

The Delphi method is particularly well suited for addressing healthcare-related issues because the outcome represents the collective judgment of the panel of experts on selected topics. The Delphi method includes three basic 
characteristics: (1) repeated individual questioning of the experts; (2) the avoidance of direct confrontation among the experts (e.g., anonymity); and (3) interspersed controlled opinion and feedback. Importantly, the Delphi method seeks to achieve consensus on complex scenarios where rigorous data are lacking. Available data on a given topic are reviewed extensively, presented, and discussed amongst the panelists. More importantly, by employing only anonymous voting by the panelists, the Delphi method settles controversy by eliminating the effects of either reputation or "personality." Consequently, anonymous voting after thorough review of the data allows the panelists to vote for what they truly believe, thus avoiding "groupthink" and sentiment guided more by "eminence," charisma, and dogmatism.

What follows is an application of the Delphi method for difficult-to-treat clinical scenarios in patients with moderate-to-severe psoriasis. This process occurred in the following three steps over approximately 5 months: (1) selection of difficult-to-treat psoriasis clinical scenarios; (2) selection of potential psoriasis treatment modalities; and (3) the matching, through systematic, iterative rounds of voting, of the clinical scenarios with the most appropriate treatments based on informed assessment of the peer-reviewed literature. At all times, the votes of the individual panelists were kept anonymous; thus, at no point was a single individual able to direct the outcome of any aspect of this process.

\section{Method Overview}

The employed Delphi exercise process is described in full in Part 1 of this study [1]. In brief, it began with the identification of 14 psoriasis experts from the United States (US). Individually, the panelists were asked to list challenging clinical scenarios and therapeutic options for psoriasis. The clinical scenarios were then selected and ranked, and the treatment options were listed. Twenty-four of the top-ranked scenarios were discussed during a live meeting and the treatment choices for each were voted on and ranked.

\section{Classification of Experimental Evidence Supporting a Therapeutic Option}

Recommendations from the Agency for Health Care Policy Research (AHCPR) were used to grade the experimental evidence as it relates to therapeutic recommendations in each case study. The categories of evidence include: level 1a: evidence from meta-analysis of randomized controlled trials (RCTs); level 1b: evidence from one or more RCT; level 2a: evidence from one or more controlled trials (without randomization); level 2b: evidence obtained through other welldesigned studies (quasi-experimental); level 3: evidence from nonexperimental studies (descriptive studies such as comparative or correlation studies, or case-control studies); level 4: expert committee opinions, clinical experience.

Preliminary recommendations for treatments were made using the best available evidence extracted from published literature. The strengths of recommendations were graded as follows: grade A: category 1 evidence; grade B: category 2 evidence or extrapolation from category 1 evidence; grade C: category 3 evidence or extrapolation from category 1 or category 2 evidence; grade D: category 4 evidence or extrapolation from category 2 or category 3 evidence.

Where definitive scientific evidence was lacking, "expert opinion" and consensus (e.g., the community standard) were used for suggested recommendations for key practical issues. 


\section{RESULTS}

Case Scenario 1. Moderate-to-Severe Psoriasis that has Failed to Respond to all Currently Approved Therapies for Psoriasis (all TNF Inhibitors, T-Cell Inhibiting Agents, and Acitretin) in Patients who Cannot Receive (a) Methotrexate, due to Excessive (>10 Drinks per Week) Alcohol Use; and (b) Cyclosporine, due to Either Unmanageable Hypertension or Significantly Reduced Kidney Function

Patients with severely recalcitrant psoriasis represent a subset of patients with comorbidities that exclude both methotrexate and cyclosporine use, but have also had no response to other options for moderate-tosevere psoriasis such as tumor necrosis factor alpha (TNF- $\alpha$ )-inhibitors, retinoids, and T-cell inhibiting agents. Currently, the data for these patients are sparse and there is frequent offlabel use.

Ustekinumab, an inhibitor of interleukin (IL) 12 and 23, presents a unique therapeutic pathway in patients who are resistant to other therapies. Ustekinumab demonstrates strong efficacy data in moderate-to-severe psoriasis (grade A evidence) [2]. Up to $67 \%$ of patients achieved a Psoriasis Area and Severity Index (PASI) score of 75 by week 12 and over $90 \%$ reached a PASI 50 by week 28. This high response rate was seen in a group of patients where over $50 \%$ had been previously treated with a biologic agent and over 55\% with a conventional systemic agent such as methotrexate, cyclosporine, acitretin, or psoralen ultraviolet A (PUVA) [2]. Among the ustekinumab partial responders, those achieving between a PASI 50 and 75 at 28 weeks, $51.9 \%$ had a prior inadequate response to a systemic or biologic agent, indicating particularly recalcitrant disease. However, increasing the dose to $90 \mathrm{mg}$ and shortening the dosing interval to 8 weeks enhanced the response and allowed more patients to reach a PASI 75 [2].

Phototherapy using broadband or narrowband ultraviolet B (UVB) therapy or PUVA is another option for these patients. In one study, narrowband UVB was superior to broadband with a higher clearance rate, faster response time, and, consequently, fewer total treatments (grade B evidence) [3]. Despite a difference in clearance rate, broadband UVB was still able to clear $73 \%$ of treated lesions. In a separate study, PUVA had even greater efficacy, with an $84 \%$ clearance rate as compared to $65 \%$ with narrowband UVB (grade A evidence) [4]. At 6 months after their initial clearance, significantly more PUVA subjects retained their results, while more narrowband UVB subjects relapsed. On the negative side, studies show that PUVA also markedly increased the risk for nonmelanoma skin carcinoma and, possibly, malignant melanoma (grade C evidence) [5].

Combinations of phototherapy with other agents have been reported, allowing it to be an adjuvant to any of the prior failed monotherapy options. Acitretin and UVB therapy have greater efficacy than UVB therapy alone (grade A evidence) [6]. The acitretin and PUVA combination also has a higher clearance rate than PUVA alone and has the additional benefit of reducing the total PUVA exposure by $42 \%$ (grade A evidence) [7]. One study focused on the treatment of patients who were refractory to monotherapy with either narrowband or broadband UVB therapy, monotherapy with acitretin, or the combination of acitretin with broadband UVB. The most successful approach in these patients was a combination of acitretin 
with narrowband UVB, which resulted in $72.5 \%$ of patients reaching a PASI 75 (grade C evidence) [8].

UV light has been combined with a few biologics, notably etanercept and alefacept. In a study of etanercept and narrowband UVB therapy, $85 \%$ of patients reached a PASI 75 after 12 weeks (grade $\mathrm{C}$ evidence) [9]. However, there were no monotherapy data for comparison, and general expectations would be a 73\% clearance rate from UVB therapy alone [3]. Using a split-body study, alefacept was able to reduce PASI scores by $62 \%$, and the addition of narrowband UVB therapy reduced the scores by $81 \%$ (grade A evidence) [10]. However, when the combination was compared to narrowband UVB therapy alone in a separate study, no significant difference was detected in patient response (grade A evidence) [11].

Some other therapeutic options include abatacept and 6-thioguanine, which are more commonly utilized in rheumatoid arthritis (RA). An initial trial of abatacept for psoriasis revealed a dose-dependent response and resulted in $46 \%$ of patients achieving a PASI 50 (grade A evidence) [12]. This improvement was seen in a population previously resistant to methotrexate, cyclosporine, phototherapy, or systemic corticosteroids. In addition, clinical improvement correlated with histological changes and reductions in T-cell activation (grade C evidence) [13]. While abatacept presents a new option for recalcitrant psoriasis, there currently is a lack of placebo-controlled studies and the optimal dose and dosing interval are unknown. In the RA population, there is an increased risk of serious infections and a higher rate of adverse events in patients with chronic obstructive pulmonary disease (COPD), and a requirement for ongoing monitoring for the risk of lung carcinoma and lymphoma (grade D evidence) [14]. For 6-thioguanine, there has been a high success rate, with $78 \%$ of patients clearing the majority, or all, of their lesions (grade C evidence) [15, 16]. Over $50 \%$ of the patients were able to maintain their results for 2 years. Despite the drug's efficacy, $35.5 \%$ of patients discontinued the therapy due to intolerable side effects. The most frequent toxicity from daily dosing is myelosuppression, found in up to $46.9 \%$ of patients. Aspartate aminotransferase (AST) and alanine aminotransferase (ALT) levels also may increase, although these elevations do not correlate with chronic liver disease. Pulse dosing has similar efficacy to daily dosing, but may lower the risk of adverse events (grade B evidence) [17].

In small clinical trials, mycophenolate mofetil reduced mean severity scores by $56 \%$ as compared with $9 \%$ for placebo (grade A evidence) [18, 19]. Over the course of treatment, significant improvement was noticeable by 6 weeks and $61 \%$ of treated patients reached a PASI 50 by week 12 (grade B evidence) [20]. Mycophenolate mofetil was also well tolerated with mild gastrointestinal effects, but the risk of leucopenia and the complications of immunosuppression remain (grade C evidence) [21].

Topical therapies may also have a role in recalcitrant psoriasis. A once-daily application of calcipotriene combined with corticosteroids was found to induce a $72 \%$ reduction in PASI scores by week 4 , which is a higher efficacy than seen with biologic agents (grade $\mathrm{C}$ evidence) [22]. However, with severe disease encompassing a large body surface area, there may arise significantly increased cost, poor patient adherence, potential hypothalamuspituitary axis suppression, and the cutaneous side effects of topical corticosteroids (grade B evidence) [23]. 


\section{Discussion}

The panelists agreed that patients with severely recalcitrant disease present a significant therapeutic challenge. Many of the participants suggested combining therapies, and, particularly, supplementing with UVB therapy or topical regimens. Azathioprine was mentioned as a potential therapy, given that 6-thioguanine is one of its metabolic products. The use of intramuscular corticosteroids was not discussed, but might remain an option for some patients who have a lessened risk for the possible adverse effects of that approach.

The top-ranked treatments for recalcitrant psoriasis include ustekinumab, narrowband UVB therapy, UV therapy + acitretin, broadband UVB therapy, PUVA, UV therapy + a biologic agent, 6-thioguanine, mycophenolate mofetil, abatacept, and topical steroids + calcipotriene. Figure 1 presents the final results of the voting by the panel on this topic. Since this Delphi Exercise was conducted ustekinumab has received approval from the US Food and Drug

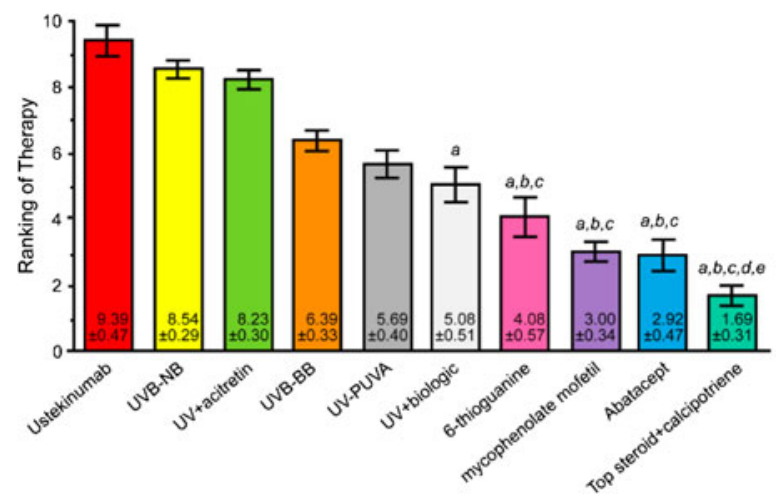

Fig. 1 Final results of the voting on case scenario 1, moderate-to-severe psoriasis that has failed to respond to all currently approved therapies for psoriasis. $a$ denotes $P<0.05$ compared with ustekinumab therapy; $b$ denotes $P<0.01$ compared with UVB-NB therapy; $c$ denotes $P<0.05$ compared with UV + acitretin therapy; $d$ denotes $P<0.01$ compared with UVB-BB therapy; $e$ denotes $P<0.05$ compared with UV-PUVA therapy. $P U V A$ psoralen + ultraviolet A therapy, $U V$ ultraviolet therapy, $U V B-B B$ broadband ultraviolet $\mathrm{B}$ therapy, $U V B$ $N B$ narrowband ultraviolet $B$ therapy
Administration for the treatment of moderateto-severe psoriasis.

Treatment Challenges: None.

\section{Case Scenario 2. PPP that is Unresponsive to Topical Therapy and Phototherapy}

While there are few data on the overall prevalence of PPP, approximately $17 \%$ of patients with psoriasis have palmar or plantar involvement (grade C evidence) [24]. Conversely, in those with PPP, a range of $2-24 \%$ will have evidence of psoriasis elsewhere [25]. However, the demographics differ in PPP from typical psoriasis, with a much higher incidence in women and a strong association to smoking (grade C evidence) [26]. Patients with palmoplantar involvement also experience higher rates of physical discomfort and disability (grade C evidence) [27].

The treatment of PPP is often challenging and may require systemic medications. A Cochrane analysis found evidence supporting the use of systemic retinoids, as the improvement rate difference over placebo was $44 \%$ and the ability to maintain clinical remission was much higher in the retinoid treatment group (grade A evidence) [28]. While the majority of studies were with etretinate, which is no longer available in the US, the analysis found that etretinate and acitretin did not differ in efficacy. PUVA shared a similar improvement rate difference of $44 \%$ above placebo. However, a combination of etretinate and oral PUVA surpassed the individual monotherapy results. The clearance rate for oral PUVA-etretinate reached $71 \%$, compared to $35 \%$ with oral PUVA alone or $20 \%$ with etretinate alone. Low-dose cyclosporine, short-course tetracycline, and Grenz ray (low voltage X-ray therapy) were 
found to improve PPP, but were unable to clear the disease. For topical therapies, the use of topical steroids under hydrocolloid occlusion was beneficial in inducing remission [28].

Several case reports suggest that the TNF- $\alpha$ inhibitors may be a viable therapeutic choice for PPP (grade D evidence) [29-32]. The various TNF- $\alpha$ inhibitors may be used in sequence with each other or in combination with acitretin (grade D evidence) [32, 33]. However, all three TNF- $\alpha$ agents, when used for the treatment of nonpsoriatic diseases, such as inflammatory bowel disease and RA, have documented incidences of inducing or exacerbating paradoxical psoriasis, with PPP representing up to $40.5 \%$ of these cases. This appears to be a class effect, as switching to a different TNF- $\alpha$ agent rarely results in a resolution of the issue. The addition of topical corticosteroids may assist in the control of this condition, while the discontinuation of the TNF- $\alpha$ inhibitor with the start of another systemic, non-TNFinhibiting agent may lead to the highest resolution rate (grade D evidence) [34].

\section{Discussion}

For PPP, some panelists shared their success with topical PUVA and cyclosporine (as monotherapy), but noted that higher doses of cyclosporine may be required. Others referred to the increased association of PPP with smoking, suggesting that cessation could be important, although the data supporting this contention are not derived from rigorous studies. Some also supported the use of acitretin by itself or as an adjunct to an existing inadequate treatment. In regard to biologic agents, a few panelists shared anecdotal successes with infliximab.

The discussion also addressed the classification of PPP as a form of psoriasis. Some suggested that PPP may be a different entity than plaque psoriasis. The TNF- $\alpha$

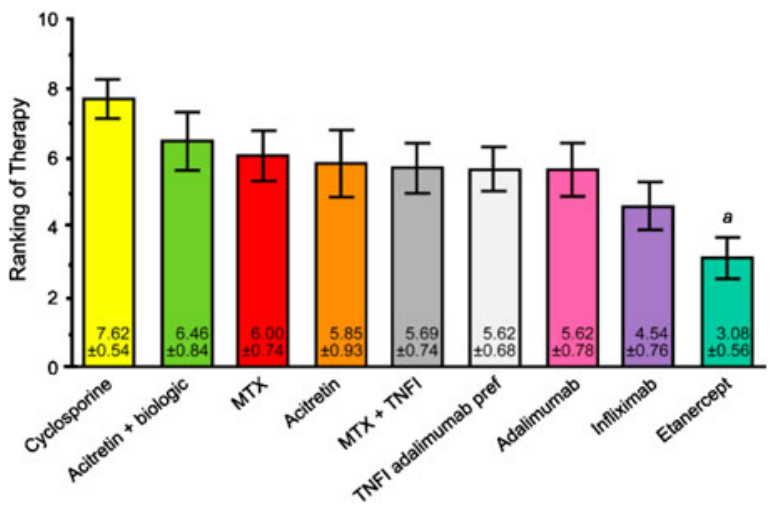

Fig. 2 Final results of the voting on case scenario 2, palmoplantar psoriasis that is unresponsive to topical therapy and phototherapy. $a$ denotes $P<0.01$ compared with cyclosporine therapy. MTX methotrexate, pref preferred, TNFI tumor necrosis factor inhibitor

inhibitor-induced psoriasis was also suggested to be a separate subset of disease due to its paradoxical induction and its relative recalcitrance to treatment.

The top-ranked treatments for PPP were cyclosporine, acitretin $+\mathrm{a}$ biologic agent, methotrexate, acitretin alone, methotrexate $+\mathrm{a}$ TNF- $\alpha$ inhibitor, TNF- $\alpha$ inhibitor (adalimumab preferred), adalimumab, infliximab, and etanercept. Figure 2 presents the final voting on PPP treatments.

Treatment Challenges: None.

\section{Case Scenario 3. Erythrodermic Psoriasis}

Hebra initially described erythroderma in 1868 as an exfoliative dermatitis involving more than $90 \%$ of the body surface, but today's definition remains nebulous as there are numerous etiologies for erythroderma. While the differential diagnosis may include systemic diseases, such as leukemia and lymphoma, a systemic drug reaction, or a paraneoplastic presentation of underlying cancer, the majority of cases arise from pre-existing skin 
disease (grade $\mathrm{C}$ evidence) $[35,36]$. Psoriasis may represent up to $40 \%$ of those cases [37]. Those with erythroderma also face a higher mortality rate than age-matched controls, and patients with psoriasis may be specifically at risk for staphylococcal septicemia (grade D evidence) [37].

Currently, there is a paucity of data to guide treatment, as erythrodermic psoriasis is almost always an exclusionary criterion in clinical trials. In a group of 33 patients, however, cyclosporine led to complete disease remission in $67 \%$ after 3 months and an overall response rate of $94 \%$ (grade B evidence) [38]. There are other also case reports supporting the efficacy of cyclosporine as a monotherapy and in combination with acitretin (grade D evidence) [39-41]. Monotherapy with both etretinate (grade A evidence) [42] and acitretin (grade C evidence) [43] demonstrated efficacy, although erythroderma was reported as a complication of acitretin use (grade D evidence) [44].

For the TNF- $\alpha$ inhibitors, there are cases of successful therapy with infliximab alone (grade D evidence) [45-48] and one case responding to a combination with cyclosporine (grade D evidence) [49]. There are no data for the use of methotrexate as monotherapy, although success with methotrexate in combination with etretinate has been reported (grade D evidence) [50]. Both adalimumab and etanercept have reports of success (grade B evidence) [51, 52]. While etanercept may take up to 24 weeks for substantial improvement, six out of 10 patients achieved a PASI 75 response.

\section{Discussion}

During the discussion of this case, panelists highlighted the differences in erythrodermic presentation. While in some cases it may be quite acute, other scenarios display a slow onset with a chronic clinical picture. With its rapid onset of action, cyclosporine was mentioned as the favored therapeutic agent for acute cases. However, if there is a delayed response to cyclosporine, then other etiologies should be considered. Aside from systemic agents, some panelists shared good results with the use of inpatient care and topical steroids. They noted that the practicality of an inpatient approach must be considered on a case-by-case basis. While etanercept was not specifically listed among the voting choices, panelists recommended that it be considered in clinical practice as there are data supporting its use.

The top-ranked treatments for erythrodermic psoriasis were cyclosporine, infliximab, methotrexate $+\mathrm{a}$ TNF- $\alpha$ inhibitor, a TNF- $\alpha$ inhibitor (infliximab preferred), adalimumab, a TNF- $\alpha$ inhibitor (adalimumab preferred), methotrexate alone, methotrexate + cyclosporine, ustekinumab, and acitretin. Figure 3 presents the results of the final voting on this issue.

Treatment Challenges: None.

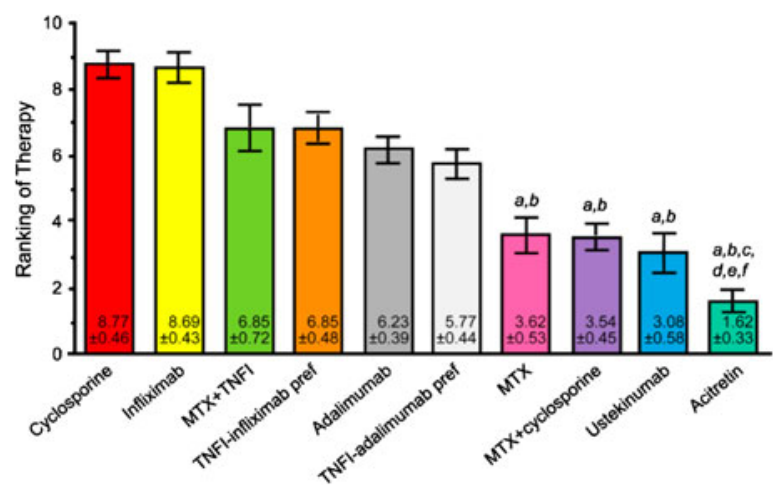

Fig. 3 Final results of the voting on case scenario 3, erythrodermic psoriasis. $a$ denotes $P<0.01$ compared with MTX therapy; $b$ denotes $P<0.01$ compared with infliximab therapy; $c$ denotes $P<0.01$ compared with MTX-TNFI therapy; $d$ denotes $P<0.01$ compared with TNFI-infliximab preferred therapy; $e$ denotes $P<0.01$ compared with adalimumab therapy; $f$ denotes $P<0.05$ compared with TNFI-adalumumab preferred therapy. MTX methotrexate, pref preferred, TNFI tumor necrosis factor inhibitor 


\section{Case Scenario 4. Pustular Psoriasis}

In general, pustular psoriasis may be categorized by distribution. The generalized form may be Von Zumbusch psoriasis, an annular subtype, or the pustular psoriasis of pregnancy known as impetigo herpetiformis. The localized variants include PPP and acrodermatitis continua. The impact on patients may range from pain and disability to life-threatening states. The etiology of pustular psoriasis includes infection, drugs, or the withdrawal of steroids. Identification of the cause is fundamental, as resolving the underlying disorder should be the first intervention. For psoriasis-specific therapy, the rapidity of the response, the ability to maintain the response, and the safety of the agent must all be considered. For generalized pustular psoriasis, there are no RCTs and the majority of clinical evidence derives from case reports.

Cyclosporine has been efficacious for generalized pustular psoriasis in its juvenile form [53], in pregnancy [54], and in adults (grade D evidence) $[55,56]$. It has a rapid onset of action. The major toxicity is from dosedependent renal damage, occurring mostly with high-dose or long-term treatment (grade A evidence) [57]. Accordingly, most recommendations are to limit cyclosporine exposure to 1-2 years, and some cases require a transition medicine for further treatment (grade D evidence) [58].

In the prevention of recurrent pustules, acitretin has been shown to be effective (grade D evidence) $[59,60]$. Etretinate has evidence for moderate improvement to complete clearance in generalized pustular psoriasis, but is no longer commercially available (grade A evidence) [42]. Acitretin has shown efficacy in children as young as 2.5 months (grade D evidence) and in adults, with visible results in fewer than 10 days (grade $C$ evidence) $[37,59]$. A recent study from France found that acitretin was the first-line treatment in $89 \%$ of cases (grade C evidence) [60]. Combining acitretin with narrowband UVB phototherapy may be synergistic, and has demonstrated efficacy for pustular psoriasis in childhood (grade D evidence) [61, 62]. Narrowband UVB therapy, with or without topical corticosteroids, is of particular use during pregnancy, when many therapeutic options have unknown teratogenic risks (grade D evidence) [63].

Methotrexate effectively treats pustular psoriasis in children (grade B evidence) [64] and adults (grade $\mathrm{C}$ evidence) [65-67]. The successful combination of methotrexate and cyclosporine for severe pustular psoriasis associated with psoriatic arthritis has also been reported (grade B evidence) [68, 69]. For the arthritis component, the combination may reduce joint inflammation, but does not alter pain levels and overall quality of life (grade A evidence) [70]. Because cyclosporine and methotrexate are associated with potential renal and hepatic damage, respectively, some have discouraged the combination due to concerns of additive toxicity (grade D evidence) [71], but dose reduction of the two individual drugs when used together may reduce risk.

A study from Japan found that retinoids had the highest success rate at $84.1 \%$, followed by methotrexate $(76.2 \%)$, cyclosporine (71.2\%), PUVA (45.7\%), and tonsillectomy for those with recurrent streptococcal pharyngitis (16.7\%) (grade C evidence) [67]. Systemic corticosteroids were also found to be efficacious when used only in the presence of severe systemic symptoms.

Of the TNF- $\alpha$ inhibitors, infliximab, etanercept, and adalimumab have evidence of efficacy. Infliximab has demonstrated both 
immediate responsiveness and long-term tolerability, often in combination with methotrexate (grade D evidence) [72-74]. There is also evidence that infliximab is beneficial for the articular disease that may be seen with pustular psoriasis (grade $\mathrm{D}$ evidence) [75]. Infliximab has a rapid onset of action, as normalization of vital signs and laboratory findings may be seen within $24 \mathrm{~h}$ of the first infusion and pustules may resolve within 24-48 h (grade D evidence) [76, 77]. Sequential therapy with infliximab for an immediate response followed by etanercept for long-term therapy has been reported (grade D evidence) [78]. Etanercept has been successful as a monotherapy in treating generalized pustular psoriasis, including in those who are unresponsive to infliximab (grade $\mathrm{D}$ evidence) [79]. Etanercept taken $50 \mathrm{mg}$ twice weekly led to significant reductions in the PASI scores of patients. The PASI scores were stably maintained over 48 weeks, even following a reduction to weekly $50 \mathrm{mg}$ dosing at 24 weeks. Adalimumab has shown efficacy in adolescence and adulthood through 72 weeks of treatment (grade D evidence) [80-82].

Patients with pustular psoriasis who are also positive for the human immunodeficiency virus (HIV) present a unique therapeutic challenge, as HIV infection is known to exacerbate psoriasis and these patients are sensitive to immunosuppression and opportunistic infection. While there are reports concerning the use of TNF- $\alpha$ inhibitors in patients with either pustular psoriasis or HIV existing separately, there is currently only one report of etanercept success in a patient with both conditions concomitantly (grade D evidence) [83]. In this, case success was maintained over a 20 week period and was not associated with any infections requiring antibiotic treatment.

\section{Discussion}

Fortunately, generalized pustular psoriasis is a rare entity. Some panelists shared their approach of treating with a medicine that is fast and useful in the short term, followed by a transition to a longer-term medication. Others stated that they preferred to use one agent, such as infliximab, throughout therapy. One panelist pointed out that some patients will have complete resolution of their disease after the initial treatment, while a subset will have recurrences.

In discussing the option of transitioning from one TNF- $\alpha$ inhibitor to another, such as infliximab to etanercept as described above, the group agreed that this approach is not commonly done. Some warned that infliximab has been shown to sometimes have a loss of efficacy with intermittent use, so that if the transition is made, the drug might no longer be an option for further use if needed later.

Overall, the majority of the panel considered cyclosporine as their first-line agent, both for its ease of prescription and rapid onset of action. Others favored infliximab as the first-line treatment. Acitretin was questioned in this setting, as its onset of action would be slower than other agents that were mentioned, but it remained an option given its recognized efficacy.

The top-ranked treatments for this condition were cyclosporine, infliximab, a TNF- $\alpha$ inhibitor (infliximab preferred), methotrexate + a TNF- $\alpha$ inhibitor, methotrexate alone, acitretin $+\mathrm{a}$ biologic agent, acitretin alone, methotrexate + cyclosporine, and UV phototherapy + acitretin. Figure 4 presents the final results of voting by the panels about treatments for pustular psoriasis.

Treatment Challenges: None. 


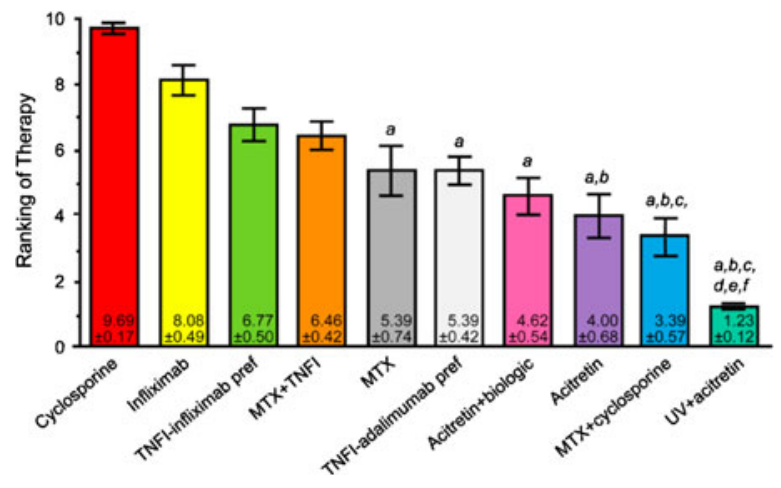

Fig. 4 Final results of the voting on case scenario 4, pustular psoriasis. a denotes $P<0.05$ compared with cyclosporine therapy; $b$ denotes $P<0.05$ compared with infliximab therapy; $c$ denotes $P<0.01$ compared with TNFI-infliximab preferred therapy; $d$ denotes $P<0.01$ compared with MTX-TNFI therapy; $e$ denotes $P<0.05$ compared with MTX therapy; $f$ denotes $P<0.05$ compared with TNFI-adalumumab preferred therapy. $M T X$ methotrexate, pref preferred, TNFI tumor necrosis factor inhibitor, $U V$ ultraviolet therapy

\section{Case Scenario 5. The Preferred Therapeutic Choice to Combine with Low-Dose Methotrexate}

In psoriasis, methotrexate has many clinical advantages. For patient safety, methotrexate has a long clinical record and well-known and uncommon side effects that may be partially preventable. For patient health, methotrexate demonstrates good efficacy for the skin and joints, no evidence of tachyphylaxis, and the ability to reduce systemic inflammation and the potentially associated cardiovascular risks. Methotrexate is also widely available at a low cost, allowing access for many patients. In addition, methotrexate is often a component of combination therapies. This discussion assessed the preferential therapeutic choices for combination with methotrexate in treating psoriasis.

The efficacy of methotrexate as a monotherapy in psoriasis has been documented over a 16 week period. Of those treated with methotrexate, $35.5 \%$ achieved a $75 \%$ reduction in the PASI score and $7.3 \%$ attained complete clearance of their skin disease (PASI 100), as compared with 18.9 and 1.9\% among placebo-treated patients, respectively (grade A evidence) [84]. However, combination therapies have been primarily examined in patients with RA, and rarely in psoriasis or psoriatic arthritis.

In RA, the addition of a TNF- $\alpha$ inhibitor to methotrexate has demonstrated superior efficacy to methotrexate monotherapy; the improvements were similar among all of the available TNF- $\alpha$ inhibitors (grade A evidence) [85]. The combination of etanercept and methotrexate enabled a significantly higher proportion of patients to reach the American College of Rheumatology (ACR) criteria of 20, 50 , or 70 reduction in tender or swollen joints, and overall disease remission (grade A evidence) [86]. At 2 years, $48.5 \%$ of patients on the combination therapy were still at ACR 70, while etanercept alone maintained only $27.4 \%$ at ACR 70 and methotrexate alone had $20.6 \%$. The addition of adalimumab to long-term methotrexate therapy has been shown to have similar effects on the ACR scores of patients over a 24 week period (grade A evidence) [87, 88]. These patients also maintained their initial 6 month response rate through a follow-up period of 4 years (grade A evidence) [89]. In methotrexate-naive patients [90] or patients with an inadequate response to methotrexate [91], this combination had the capacity to slow radiographic progression of the disease (grade $\mathrm{A}$ evidence). Infliximab trials also supported improved response rates in combination therapy as an ACR 50 was found in 31\% of patients compared with 5\% from methotrexate alone (grade A evidence) [92]. A separate study with methotrexate-naive subjects analyzed response rates and systemic inflammatory 
markers from high-dose methotrexate with or without infliximab (grade A evidence) [93]. While methotrexate was able to improve disease control, it did not prevent radiographic deterioration of joints in those with high baseline levels of pre-existing joint disease and those with high systemic inflammation evident from CRP and erythrocyte sedimentation rate (ESR) levels. However, the combination of methotrexate and infliximab was successful in inhibiting joint disease progression in this subset of patients.

There is emerging evidence that early, aggressive intervention with combination therapies may be best for long-term outcomes in patients with RA. The success with methotrexate monotherapy was similar in early (diagnosed within the past 2 years) or established RA, but the combination therapy with adalimumab was significantly more effective in achieving ACR 70 levels in early RA, with $41 \%$ of early RA subjects responding, compared with $18 \%$ of established RA subjects (grade A evidence) [91].

In contrast to RA, the literature on psoriasis or psoriatic arthritis is sparse. In patients with plaque psoriasis who responded inadequately to methotrexate as monotherapy, after the addition of etanercept, significantly more patients were at "clear" to "almost clear" in the Physician's Global Assessment (PGA), and almost twice as many patients achieved PASI 75. Importantly, there was less of a response in those in whom methotrexate was tapered after the addition of etanercept (grade $\mathrm{B}$ evidence) [94]. Adalimumab was shown to improve ACR and PASI scores when used with methotrexate, but this was only statistically significant for PASI 50 (grade A evidence) [95]. Alefacept and methotrexate have been successful in the treatment of psoriasis, with $53 \%$ of patients on the combination therapy reaching PASI 50, a significant increase from $17 \%$ with methotrexate monotherapy (grade A evidence) [96]. For the psoriatic arthritis component, methotrexate alone only reached an ACR 20 response in $17 \%$ of patients, while the combination with alefacept achieved the response in 54\%. An open-label extension of this study demonstrated that patients might benefit from a second course of alefacept, supplementing a stable methotrexate dose, as more patients reached ACR 50 and ACR 70 with the repeated combination (grade $B$ evidence) [97].

\section{Discussion}

Overall, the panelists emphasized the lack of psoriasis-specific data for agents to combine with methotrexate and noted that most of the evidence and conclusions available are based on extrapolations from the RA data. In addition, while combination therapies may be effective, they each have their own set of individual risk profiles and patient comorbidities that may limit therapeutic options.

The combination of cyclosporine and methotrexate was suggested with great trepidation. Initial data suggested utility in the control of skin and joint disease at lower doses in combination than either would require as a monotherapy. However, renal toxicity, which is not reversible with cyclosporine taper, was detected on long-term combination treatment (grade B evidence) [69]. In a separate study of patients with plaque, pustular, or erythrodermic psoriasis, with or without arthritis, the combination of cyclosporine and methotrexate reduced PASI scores by a median of $77.4 \%$, but also induced a proportion of patients to develop altered renal or liver function (grade B evidence) [68]. Panelist opinion varied on this subject, with some using this combination frequently, others refusing to use the combination after 


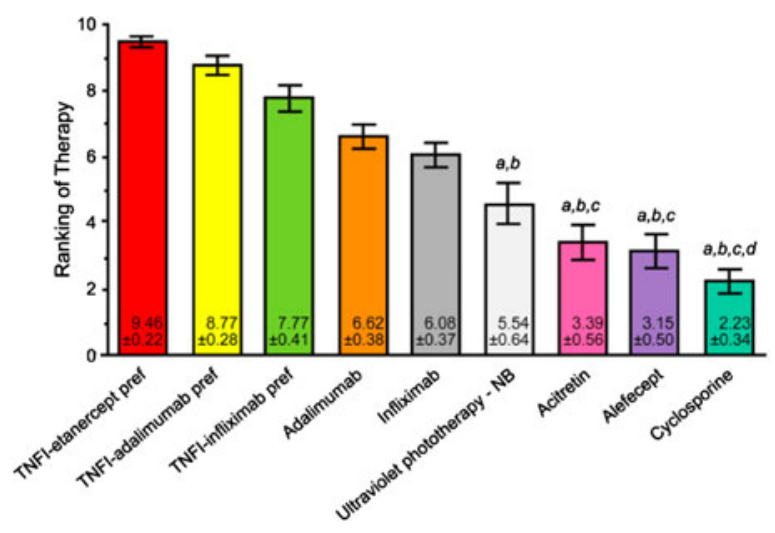

Fig. 5 Final results of the voting on case scenario 5, the preferred therapeutic choice for combination with methotrexate. $a$ denotes $P<0.01$ compared with TNFIetanercept preferred therapy; $b$ denotes $P<0.05$ compared with TNFI-adalimumab preferred therapy; $c$ denotes $P<0.05$ compared with TNFI-infliximab preferred therapy; $d$ denotes $P<0.05$ compared with adalimumab therapy. $N B$ narrowband, pref preferred, TNFI tumor necrosis factor inhibitor

experience with significant adverse events, and others replacing cyclosporine with biologic agents.

The top-ranked treatments for this case scenario were a TNF- $\alpha$ inhibitor (etanercept preferred), a TNF- $\alpha$ inhibitor (adalimumab preferred), a TNF- $\alpha$ inhibitor (infliximab preferred), adalimumab, infliximab, narrowband UV therapy, acitretin, alefacept, and cyclosporine. Figure 5 presents the results of the final round of voting.

Treatment Challenges: None.

\section{DISCUSSION}

This investigation further employs the Delphi process to determine acceptable treatment recommendations in difficult-to-treat psoriasis patients. An additional five case scenarios discussed at the live meeting are presented in this paper: moderate-to-severe psoriasis that has failed to respond to all currently approved therapies for psoriasis in patients who cannot receive methotrexate or cyclosporine; PPP that is unresponsive to topical therapy and phototherapy; erythrodermic psoriasis; pustular psoriasis; and the preferred therapeutic choice to combine with low-dose methotrexate. Six other cases were presented in a separate article [1].

As described previously, the iterative and anonymous voting process of the Delphi method depends on an unbiased view of the available clinical data and leads to more objective consensus. The final rankings should be viewed as guidance for practical, potentially effective, and likely safe treatment in a majority of instances. Because the Delphi method does not introduce better data for a given topic, it cannot produce an idealized outcome. The process we have utilized selects rational treatment choices for each clinical scenario, but these choices often are not supported by rigorous studies. Importantly, this evidencebased approach relying on anonymous opinion is a more objective tool for reaching consensus. The process has multiple limitations, all enumerated in Part 1 of this analysis [1]; however, the Delphi exercise helps clinicians in practice benefit from more objective consensus opinion, offering guidance during challenging clinical scenarios, and allowing for the use of specific treatment approaches that often are effective and safe.

\section{ACKNOWLEDGMENTS}

The Delphi exercise and meeting was supported by educational Grants from Abbott Laboratories, Amgen, Astellas, Galderma, and Genentech, and held in association with Millennium CME Institute, Inc., and Advances 
in Cosmetic and Medical Dermatology: Maui Derm.

Conflict of interest. All of the authors disclose that they received support for travel and an honorarium for participating in the Delphi exercise. J.C.C. discloses that she has received honoraria from Abbott, Amgen, Centocor, Eisai, and Genentech for speaking and consulting. D.C. discloses that he has received honoraria from Abbott, Amgen, Galderma, Johnson \& Johnson, Steifel, and Viewpoint Securities for speaking and consulting. J.J.C. discloses that he has received honoraria from Abbott, Amgen, and Genentech for speaking and consulting. K.B.G. discloses that he has received honoraria and Grants from Abbott, Amgen, Centocor, and Gladerma for Grants and consulting. A.G. discloses that she has received honoraria from Acetelion, Almirall, Amgen, Beiersdorf, Bristol-Myers Squibb, CanFite, Celera, Celgene, Centocor, Corgentech, Cytokine, Dermipsor, Immune Control, Incyte, Kemia, Magen Biosciences, Medarex, Novo Nordisk, PureTech, RxClinical, Roche, Sankyo, Teva, UCB, Warner Chilcott, Wyeth for speaking and consulting; almost all income from these activities was paid directly to her employer. She has received research/ educational Grants from Abbott, Amgen, Celgene, Centocor, Immune Control, Incyte, and Wyeth. A.F.K. discloses that he has received honoraria from Abbott, Amgen, Biogen Idec, Centocor, and UCB to support research studies. N.J.K. discloses that he has received honoraria from Abbott, Amgen, Astellas, Celggene, Centocor, Genentech, Genmab, Kemia, Novartis, Peplin, and Watson for speaking, consulting, and for research studies. G.G.K. discloses that he has received honoraria from Abbott, Almirall, Alza, Amgen, Anacor, Astellas, Barrier Therapeutics, Boehringer Ingelheim,
Bristol-Myers Squibb, Centocor, CombinationRx, Exelixis, Genentech, Genzyme, Isis, L'Oreal, Lupin Limited, Magen Biosciences, MedaCorp, Medicis, Novartis, Nova Nordisc, Schering Plough, Somagenics, theDerm.org, Synvista, Warner Chilcott, UCB, USANA Health Sciences, and ZARS for speaking and consulting. He owns equities and stock options in ZARS. He has received partial stipend support for a clinical research fellowship from Abbott, Amgen, and Centocor. C.L.L. discloses that he has received honoraria from Abbott and Amgen for speaking and from Abbott, Amgen, Centocor, Eli Lilly, and Pfizer, Inc., for consulting. He has received research grant support from Abbott, Amgen, Anacor, Celgene, Centocor, Eli Lilly, Galderma, GlazoSmithKline, Incyte, Maruho, Novartis, Novo Nordisk, Pfizer, Inc., Schering Plough, Sirtris, Stiefel, Vascular Biogenic, and Wyeth. S.S. discloses that he has received honoraria from Abbott, Centocor, Genentech, and UCB for speaking and consulting. J.M.S. discloses that he has received honoraria from Abbott, Amgen, Centocor, and Genentech for speaking and consulting. G.E.S. has no disclosures other than that cited above for all participants. M.Y. discloses that she has received honoraria from Abbott, Amgen, Astellas, Centocor, and Genentech for speaking and consulting. B.E.S. discloses that he has received honoraria for consulting from Abbott, Amgen, Celgene, Centocor/Johnson \& Johnson, Galderma, Leo, Maruho, and Novartis. Editorial assistance in the preparation of this article was provided by an independent medical editor, Nancy Monson. B.E.S. is the guarantor for this article, and takes responsibility for the integrity of the work as a whole.

Open Access. This article is distributed under the terms of the Creative Commons Attribution Noncommercial License which 
permits any noncommercial use, distribution, and reproduction in any medium, provided the original author(s) and source are credited.

\section{REFERENCES}

1. Strober BE, Clay Cather J, Cohen D et al. A Delphi consensus approach to challenging case scenarios in moderate-to-severe psoriasis: part 1 . Dermatol Ther. 2012;2:1.

2. Leonardi CL, Kimball AB, Papp KA, et al. Efficacy and safety of ustekinumab, a human interleukin$12 / 23$ monoclonal antibody, in patients with psoriasis: 76 week results from a randomised, double-blind, placebo-controlled trial (PHOENIX 1). Lancet. 2008;371:1665-74.

3. Coven TR, Burack LH, Gilleaudea U, Keogh M, Ozawa M, Krueger JG. Narrowband UV-B produces superior clinical and histopathological resolution of moderate-to-severe psoriasis in patients compared with broadband UV-B. Arch Dermatol. 1997;133: 1514-22.

4. Yones SS, Palmer RA, Garibaldinos TT, Hawk JL. Randomized double-blind trial of the treatment of chronic plaque psoriasis: efficacy of psoralen-UV-A therapy vs narrowband UV-B therapy. Arch Dermatol. 2006;142:836-42.

5. Stern RS, Nichols KT, Vakeva LH. Malignant melanoma in patients treated for psoriasis with methoxsalen (psoralen) and ultraviolet A radiation (PUVA). The PUVA follow-up study. N Engl J Med. 1997;336:1041-5.

6. Ruzicka T, Sommerburg C, Braun-Falco O, et al. Efficiency of acitretin in combination with UV-B in the treatment of severe psoriasis. Arch Dermatol. 1990;126:482-6.

7. Tanew A, Guggenbichler A, Honigsmann H, Geiger JM, Fritsch P. Photochemotherapy for severe psoriasis without or in combination with acitretin: a randomized, double-blind comparison study. J Am Acad Dermatol. 1991;25:682-4.

8. Spuls PI, Rozenblit M, Lebwohl M. Retrospective study of the efficacy of narrowband UVB and acitretin. J Dermatol Treat. 2003;4:17-20.

9. Kircik L, Bagel J, Korman N, et al. Utilization of narrow-band ultraviolet light $\mathrm{B}$ therapy and etanercept for the treatment of psoriasis (UNITE): efficacy, safety, and patient-reported outcomes. J Drugs Dermatol. 2008;7:245-53.
10. Legat FJ, Hofer A, Wackernagel A, et al. Narrowband UV-B phototherapy, alefacept, and clearance of psoriasis. Arch Dermatol. 2007;143:1016-22.

11. Jacobe H, Winterfield L, Kim F, Huet-Adams B, Cayce R. The role of narrowband UV-B plus alefacept combination therapy in the treatment of psoriasis. Arch Dermatol. 2008;144:1067-8. author reply: 1068-1069.

12. Abrams JR, Lebwohl MG, Guzzo CA, et al. CTLA4Igmediated blockade of T-cell costimulation in patients with psoriasis vulgaris. J Clin Invest. 1999;103:1243-52.

13. Abrams JR, Kelley SL, Hayes E, et al. Blockade of T lymphocyte costimulation with cytotoxic $\mathrm{T}$ lymphocyte-associated antigen 4-immunoglobulin (CTLA4Ig) reverses the cellular pathology of psoriatic plaques, including the activation of keratinocytes, dendritic cells, and endothelial cells. J Exp Med. 2000;192:681-94.

14. DE Furst, Breedveld FC, Kalden Jr. Updated consensus statement on biological agents for the treatment of rheumatic diseases, 2007. Ann Rheum Dis. 2007;66(Suppl. 3):iii2-22.

15. Zackheim HS, Glogau RG, Fisher DA, Maibach H. 6-Thioguanine treatment of psoriasis: experience in 81 patients. J Am Acad Dermatol. 1994;30:452-8.

16. Sherer DW, Lebwohl MG. 6-thioguanine in the treatment of psoriasis: a case report and literature review. J Cutan Med Surg. 2002;6:546-50.

17. Silvis NG, Levine N. Pulse dosing of thioguanine in recalcitrant psoriasis. Arch Dermatol. 1999;135:433-7.

18. Gomez EC, Menendez L, Frost P. Efficacy of mycophenolic acid for the treatment of psoriasis. J Am Acad Dermatol. 1979;1:531-7.

19. Spatz S, Rudnicka A, McDonald CJ. Mycophenolic acid in psoriasis. Br J Dermatol. 1978;98:429-35.

20. Zhou Y, Rosenthal D, Dutz J, Ho V. Mycophenolate mofetil (CellCept) for psoriasis: a two-center, prospective, open-label clinical trial. J Cutan Med Surg. 2003;7:193-7.

21. Buell C, Koo J. Long-term safety of mycophenolate mofetil and cyclosporine: a review. J Drugs Dermatol. 2008;7:741-8.

22. Menter A, Ganslandt C. Comparative efficacy of calcipotriene/betamethasone dipropionate combination product after 1, 2, and 4 weeks of treatment of mild, moderate, and severe psoriasis. 2006 Annual Meeting of the American Academy of Dermatology. J Am Acad Dermatol. 2006;54:AB215. 
23. Kragballe K, Austad J, Barnes L, et al. A 52 week randomized safety study of a calcipotriol/ betamethasone dipropionate two-compound product (Dovobet/Daivobet/Taclonex) in the treatment of psoriasis vulgaris. $\mathrm{Br} \mathrm{J}$ Dermatol. 2006;154:1155-60.

24. Kumar B, Saraswat A, Kaur I. Palmoplantar lesions in psoriasis: a study of 3,065 patients. Acta Derm Venereol. 2002;82:192-5.

25. Enfors W, Molin L. Pustulosis palmaris et plantaris. A follow-up study of a ten-year material. Acta Derm Venereol. 1971;51:289-94.

26. Langley RG, Krueger GG, Griffiths CE. Psoriasis: epidemiology, clinical features, and quality of life. Ann Rheum Dis. 2005;64(Suppl. 2):ii18-23. discussion: ii24-ii25.

27. Pettey AA, Balkrishnan R, Rapp SR, Fleischer AB, Feldman SR. Patients with palmoplantar psoriasis have more physical disability and discomfort than patients with other forms of psoriasis: implications for clinical practice. J Am Acad Dermatol. 2003;49:271-5

28. Marsland AM, Chalmers RJ, Hollis S, Leonardi-Bee J, Griffiths CE. Interventions for chronic palmoplantar pustulosis. Cochrane Database Syst Rev. 2006;CD001433.

29. Bissonnette R, Poulin Y, Bolduc C, et al. Etanercept in the treatment of palmoplantar pustulosis. J Drugs Dermatol. 2008;7:940-6.

30. Weinberg JM. Successful treatment of recalcitrant palmoplantar psoriasis with etanercept. Cutis. 2003;72:396-8.

31. Ahmad K, Rogers S. Three years' experience with infliximab in recalcitrant psoriasis. Clin Exp Dermatol. 2006;31:630-3.

32. Yawalkar N, Hunger RE. Successful treatment of recalcitrant palmoplantar pustular psoriasis with sequential use of infliximab and adalimumab. Dermatology. 2009;218:79-83.

33. Tobin AM, Kirby B. Successful treatment of recalcitrant acrodermatitis continua of Hallopeau with adalimumab and acitretin. Br J Dermatol. 2005;153:445-6.

34. Kalb RE, Bagel J, Korman NJ, et al. Treatment of intertriginous psoriasis: from the Medical Board of the National Psoriasis Foundation. J Am Acad Dermatol. 2009;60:120-4.

35. Rym BM, Mourad M, Bechir Z, et al. Erythroderma in adults: a report of 80 cases. Int J Dermatol. 2005;44:731-5.
36. Sigurdsson V, Toonstra J, Hezemans-Boer $M$, van Vloten WA. Erythroderma. A clinical and follow-up study of 102 patients, with special emphasis on survival. J Am Acad Dermatol. 1996;35:53-7.

37. Green MS, Prystowsky JH, Cohen SR, Cohen JI, Lebwohl MG. Infectious complications of erythrodermic psoriasis. J Am Acad Dermatol. 1996;34:911-4.

38. Studio Italiano Multicentrico nella Psoriasi (SIMPSO). Management of erythrodermic psoriasis with low-dose cyclosporin. Dermatology. 1993; 187:30-7.

39. Picascia DD, Garden JM, Freinkel RK, Roenigk HH Jr. Treatment of resistant severe psoriasis with systemic cyclosporine. J Am Acad Dermatol. 1987; 17:408-14.

40. Kokelj F, Plozzer C, Torsello P, Trevisan G. Efficacy of cyclosporine plus etretinate in the treatment of erythrodermic psoriasis (three case reports). J Eur Acad Dermatol Venereol. 1998;11:177-9.

41. Kuijpers AL, van Dooren-Greeben JL, van de Kerkhof JC. Failure of combination therapy with acitretin and cyclosporin A in 3 patients with erythrodermic psoriasis. Dermatology. 1997;194:88-90.

42. Wolska H, Jablonska S, Bounameaux Y. Etretinate in severe psoriasis. Results of double-blind study and maintenance therapy in pustular psoriasis. J Am Acad Dermatol. 1983;9:883-9.

43. Pang ML, Murase JE, Koo J. An updated review of acitretin-a systemic retinoid for the treatment of psoriasis. Expert Opin Drug Metab Toxicol. 2008;4: 953-64.

44. Ahdout J, Mandel H, Chiu M. Erythroderma in a patient taking acitretin for plaque psoriasis. J Drugs Dermatol. 2008;7:391-4.

45. Rongioletti F, Borenstein M, Kirsner R, Kerdel F. Erythrodermic, recalcitrant psoriasis: clinical resolution with infliximab. J Dermatol Treat. 2003;14:222-5.

46. Lisby S, Gniadecki R. Infliximab (Remicade) for acute, severe pustular and erythrodermic psoriasis. Acta Derm Venereol. 2004;84:247-8.

47. Lewis TG, Tuchinda C, Lim HW, Wong HK. Lifethreatening pustular and erythrodermic psoriasis responding to infliximab. J Drugs Dermatol. 2006;5:546-8.

48. Takahashi MD, Castro LG, Romiti R. Infliximab, as sole or combined therapy, induces rapid clearing of erythrodermic psoriasis. Br J Dermatol. 2007;157: 828-31. 
49. Pedraz J, Sanz T, Garcia-Diez A. Cyclosporin A effectively controls recalcitrant psoriasis resistant to biologic therapy. J Am Acad Dermatol. 2007;56: AB180.

50. Tuyp E, MacKie RM. Combination therapy for psoriasis with methotrexate and etretinate. J Am Acad Dermatol. 1986;14:70-3.

51. Esposito M, Mazzotta A, de Felice C, Papoutsaki M, Chimentis S. Treatment of erythrodermic psoriasis with etanercept. Br J Dermatol. 2006;155:156-9.

52. Papoutsaki M, Chimenti, Talamonti M, Chimenti S. Long-term efficacy of adalimumab for the treatment of psoriasis and psoriatic arthritis. J Am Acad Dermatol. 2007;56:AB175.

53. Xiao T, Li B, He CD, Chen HD. Juvenile generalized pustular psoriasis. J Dermatol. 2007;34:573-6.

54. Kapoor R, Kapoor JR. Cyclosporine resolves generalized pustular psoriasis of pregnancy. Arch Dermatol. 2006;142:1373-5.

55. Kawakami Y, Oyama N, Kishimoto K, et al. A case of generalized pustular psoriasis associated with Turner syndrome. J Dermatol. 2004;31:16-20.

56. Umezawa Y, Ozawa A, Kawasima $\mathrm{T}$, et al. Therapeutic guidelines for the treatment of generalized pustular psoriasis (GPP) based on a proposed classification of disease severity. Arch Dermatol Res. 2003;295:S43-54.

57. Vercauteren SB, Bosmans JL, Elseviers MM, Verpooten GA, De Broe ME. A meta-analysis and morphological review of cyclosporine-induced nephrotoxicity in auto-immune diseases. Kidney Int. 1998;54:536-45.

58. Griffiths CE, Dubertret L, Ellis CN, et al. Ciclosporin in psoriasis clinical practice: an international consensus statement. Br J Dermatol. 2004;150:11-23.

59. Ergin S, Ersoy-Evans S, Sahin S, Ozkaya O. Acitretin is a safe treatment option for infantile pustular psoriasis. J Dermatol Treat. 2008;19:341-3.

60. Augey F, Renaudier P, Nicolas JF. Generalized pustular psoriasis (Zumbusch): a French epidemiological survey. Eur J Dermatol. 2006;16:669-73.

61. Kopp T, Karlhofer F, Szepfalusi Z, Schneeberger A, Stingl $\mathrm{G}$, Tanew A. Successful use of acitretin in conjunction with narrowband ultraviolet B phototherapy in a child with severe pustular psoriasis, von Zumbusch type. Br J Dermatol. 2004;151:912-6.

62. Van Zander J, Orlow SJ. Efficacy and safety of oral retinoids in psoriasis. Expert Opin Drug Saf. 2005;4:129-38.
63. Yun $\mathrm{Y}$, Jones B, Al-Mudhaffer $\mathrm{M}$, Egan C. Generalized pustular psoriasis of pregnancy treated with narrowband UVB and topical steroids. J Am Acad Dermatol. 2006;54:S28-30.

64. Kaur I, Dogra S, De D, Kanwar AJ. Systemic methotrexate treatment in childhood psoriasis: further experience in 24 children from India. Pediatr Dermatol. 2008;25:184-8.

65. Kuijpers AL, van de Kerkhof PC. Risk-benefit assessment of methotrexate in the treatment of severe psoriasis. Am J Clin Dermatol. 2000;1:27-39.

66. Haustein UF, Rytter M. Methotrexate in psoriasis: 26 years' experience with low-dose long-term treatment. J Eur Acad Dermatol Venereol. 2000;14:382-8.

67. Ozawa A, Ohkido M, Haruki Y, et al. Treatments of generalized pustular psoriasis: a multicenter study in Japan. J Dermatol. 1999;26:141-9.

68. Aydin F, Canturk T, Senturk N, Turani AY. Methotrexate and ciclosporin combination for the treatment of severe psoriasis. Clin Exp Dermatol. 2006;31:520-4.

69. Clark CM, Kirby B, Morris AD, et al. Combination treatment with methotrexate and cyclosporin for severe recalcitrant psoriasis. $\mathrm{Br} \mathrm{J}$ Dermatol. 1999;141:279-82.

70. Fraser AD, van Kuijk AW, Westhovens R, et al. A randomised, double blind, placebo controlled, multicentre trial of combination therapy with methotrexate plus ciclosporin in patients with active psoriatic arthritis. Ann Rheum Dis. 2005; 64:859-64.

71. Korstanje MJ, van Breda Vriesman CJ, van de Staak WJ. Cyclosporine and methotrexate: a dangerous combination. J Am Acad Dermatol. 1990;23:320-1.

72. Elewski BE. Infliximab for the treatment of severe pustular psoriasis. J Am Acad Dermatol. 2002;47: 796-7.

73. Varma R, Cafardi JA, Cantrell W, Elmet C. Safety and efficacy of subcutaneously administered efalizumab in adults with moderate-to-severe hand and foot psoriasis: an open-label study. Am J Clin Dermatol. 2008;9:105-9.

74. Routhouska SB, Sheth PB, Korman NJ. Long-term management of generalized pustular psoriasis with infliximab: case series. J Cutan Med Surg. 2008;12:184-8.

75. Vieira Serrao V, Martins A, Lopes MJ. Infliximab in recalcitrant generalized pustular arthropatic psoriasis. Eur J Dermatol. 2008;18:71-3. 
76. Trent JT, Kerdel FA. Successful treatment of Von Zumbusch pustular psoriasis with infliximab. J Cutan Med Surg. 2004;8:224-8.

77. Weishaupt C, Metze D, Luger TA, Stander S. Treatment of pustular psoriasis with infliximab. J Dtsch Dermatol Ges. 2007;5:397-9.

78. Weisenseel P, Prinz JC. Sequential use of infliximab and etanercept in generalized pustular psoriasis. Cutis. 2006;78:197-9.

79. Esposito M, Mazzotta A, Casciello C, Chimenti S. Etanercept at different dosages in the treatment of generalized pustular psoriasis: a case series. Dermatology. 2008;216:355-60.

80. Zangrilli A, Papoutsaki M, Talmonti M, Chimenti S. Long-term efficacy of adalimumab in generalized pustular psoriasis. J Dermatol Treat. 2008;19:185-7.

81. Jordan J, Bieber T, Wilsmann-Theis D. Adalimumab: safe and successful in severe pustular psoriasis. J Eur Acad Dermatol Venereol. 2009;23:592-3.

82. Callen JP, Jackson JH. Adalimumab effectively controlled recalcitrant generalized pustular psoriasis in an adolescent. J Dermatol Treat. 2005;16:350-2.

83. Mikhail M, Weinberg JM, Smith BL. Successful treatment with etanercept of von Zumbusch pustular psoriasis in a patient with human immunodeficiency virus. Arch Dermatol. 2008;144:453-6.

84. Saurat JH, Stingl G, Dubertret L, et al. Efficacy and safety results from the randomized controlled comparative study of adalimumab vs. methotrexate vs. placebo in patients with psoriasis (CHAMPION). Br J Dermatol. 2008;158:558-66.

85. Hochberg MC, Tracy JK, Hawkins-Holt M, Flores RH. Comparison of the efficacy of the tumour necrosis factor alpha blocking agents adalimumab, etanercept, and infliximab when added to methotrexate in patients with active rheumatoid arthritis. Ann Rheum Dis. 2003;62:ii13-6.

86. van der Heijde D, Klareskog L, Rodriguez-Valverde $\mathrm{V}$, et al. Comparison of etanercept and methotrexate, alone and combined, in the treatment of rheumatoid arthritis: two-year clinical and radiographic results from the TEMPO study, a double-blind, randomized trial. Arthr Rheum. 2006;54:1063-74.

87. Weinblatt ME, Keystone EC, Furst DE, et al. Adalimumab, a fully human anti-tumor necrosis factor alpha monoclonal antibody, for the treatment of rheumatoid arthritis in patients taking concomitant methotrexate: the ARMADA trial. Arthr Rheum. 2003;48:35-45.
88. Chen DY, Chou SJ, Hseih TY, et al. Randomized, double-blind, placebo-controlled, comparative study of human anti-TNF antibody adalimumab in combination with methotrexate and methotrexate alone in Taiwanese patients with active rheumatoid arthritis. J Formos Med Assoc. 2009;108:310-9.

89. Solomon DH, Avorn J, Katz JN, et al. Immunosuppressive medications and hospitalization for cardiovascular events in patients with rheumatoid arthritis. Arthr Rheum. 2006;54:3790-8.

90. Breedveld FC, Weisman MH, Kavanaugh AF, et al. The PREMIER study: a multicenter, randomized, double-blind clinical trial of combination therapy with adalimumab plus methotrexate versus methotrexate alone or adalimumab alone in patients with early, aggressive rheumatoid arthritis who had not had previous methotrexate treatment. Arthr Rheum. 2006;54:6-37.

91. Keystone EC, Haraoui B, Bykerk VP. Role of adalimumab in the treatment of early rheumatoid arthritis. Clin Exp Rheumatol. 2003;21(5 Suppl. 31):S198-9.

92. Maini R, St Clair EW, Breedveld F, et al. Infliximab (chimeric anti-tumour necrosis factor alpha monoclonal antibody) versus placebo in rheumatoid arthritis patients receiving concomitant methotrexate: a randomised phase III trial. ATTRACT Study Group. Lancet. 1999;354:1932-9.

93. Smolen JS, Van Der Heijde DM, St Clair EW, et al. Predictors of joint damage in patients with early rheumatoid arthritis treated with high-dose methotrexate with or without concomitant infliximab: results from the ASPIRE trial. Arthr Rheum. 2006;54:702-10.

94. Zachariae C, Mork NJ, Reunala T, et al. The combination of etanercept and methotrexate increases the effectiveness of treatment in active psoriasis despite inadequate effect of methotrexate therapy. Acta Derm Venereol. 2008;88:495-501.

95. Gladman DD, Mease PJ, Ritchlin CT, et al. Adalimumab for long-term treatment of psoriatic arthritis: forty-eight week data from the adalimumab effectiveness in psoriatic arthritis trial. Arthr Rheum. 2007;56:476-88.

96. Mease PJ, Gladman DD, Keystone EC. Alefacept in combination with methotrexate for the treatment of psoriatic arthritis: results of a randomized, double-blind, placebo-controlled study. Arthr Rheum. 2006;54:1638-45.

97. Mease PJ, Reich K. Alefacept with methotrexate for treatment of psoriatic arthritis: open-label extension of a randomized, double-blind, placebo-controlled study. J Am Acad Dermatol. 2009;60:402-11. 